\title{
Getting published in Radiology: A Deputy Editor's perspective
}

\author{
Ali Guermazi ${ }^{1} \cdot$ Herbert Y. Kressel $^{2}$
}

Received: 30 June 2015 / Accepted: 27 July 2015 / Published online: 5 August 2015

(C) Japan Radiological Society 2015

\begin{abstract}
Radiology has been the official journal of the Radiological Society of North America since 1923. In 2014 it had an impact factor of 6.867, the highest for general radiology journals. The journal attracts a world-wide readership of approximately 54,000. Contributions from Japanese radiologists, radiographers, and radiological scientists are greatly welcomed. This article explains how we process the manuscripts submitted to the journal and describes the factors that can contribute to the decision to accept or reject.
\end{abstract}

Keywords Radiology $\cdot$ Radiological Society of North America (RSNA) $\cdot$ Publication $\cdot$ Research

\section{General overview and statistics}

We review approximately 3000 manuscripts per year, $35 \%$ of which come from North America. After external peer review, approximately 350 original research papers are published every year. Overall acceptance of manuscripts is $15 \%$; that for original research papers is $12 \%$. In 2014 the average time between manuscript submission and the initial editorial decision was 31 days. Each month, the journal publishes approximately 300 pages of peer-reviewed original research, authoritative reviews, well-balanced

Ali Guermazi

guermazi@bu.edu

1 Department of Radiology, Boston University School of Medicine, 820 Harrison Avenue, FGH Building, 3rd Floor, Boston, MA 02118, USA

2 Department of Radiology, Beth Israel Deaconess Medical Center, Harvard Medical School, Boston 02215, MA, USA commentary on significant articles, and expert opinion on new techniques and technology. We regularly publish results from large studies from several ongoing multicenter research programs, including the American College of Radiology Imaging Network (ACRIN), the Alzheimer's Disease Neuroimaging Initiative (ADNI), the Multi-Ethnic Study of Atherosclerosis (MESA), and the Dallas Heart Study.

\section{Contributions from Japanese authors}

In 2014 we were fortunate to receive 166 manuscripts from Japanese authors (i.e. the primary institution of the first author is in Japan) for consideration for publication in Radiology. Seventeen of the journal's original research papers were written by Japanese authors; this acceptance rate, $10.2 \%$, is in keeping with our general acceptance figure of $12 \%$. Of these, two highly cited papers are worth mentioning here-a paper by Kanda et al. in the Neuroradiology section [1] and a paper by Satoh et al. in the Oncologic Imaging section [2]. We currently have two Japanese radiologists serving as Associated Editors of Radiology, Osamu Matsui, MD and Hiromu Mori, MD. Since July 1, 2013 we have also had 14 active reviewers from Japan.

\section{Manuscript preparation and review process}

Manuscripts should be submitted via our online submission system (http://mc.manuscriptcentral.com/rad). Authors should read the "Publication Information for Authors" available online (http://pubs.rsna.org/page/radiology/pia) [3], where we have assembled an "author toolkit" to aid authors 


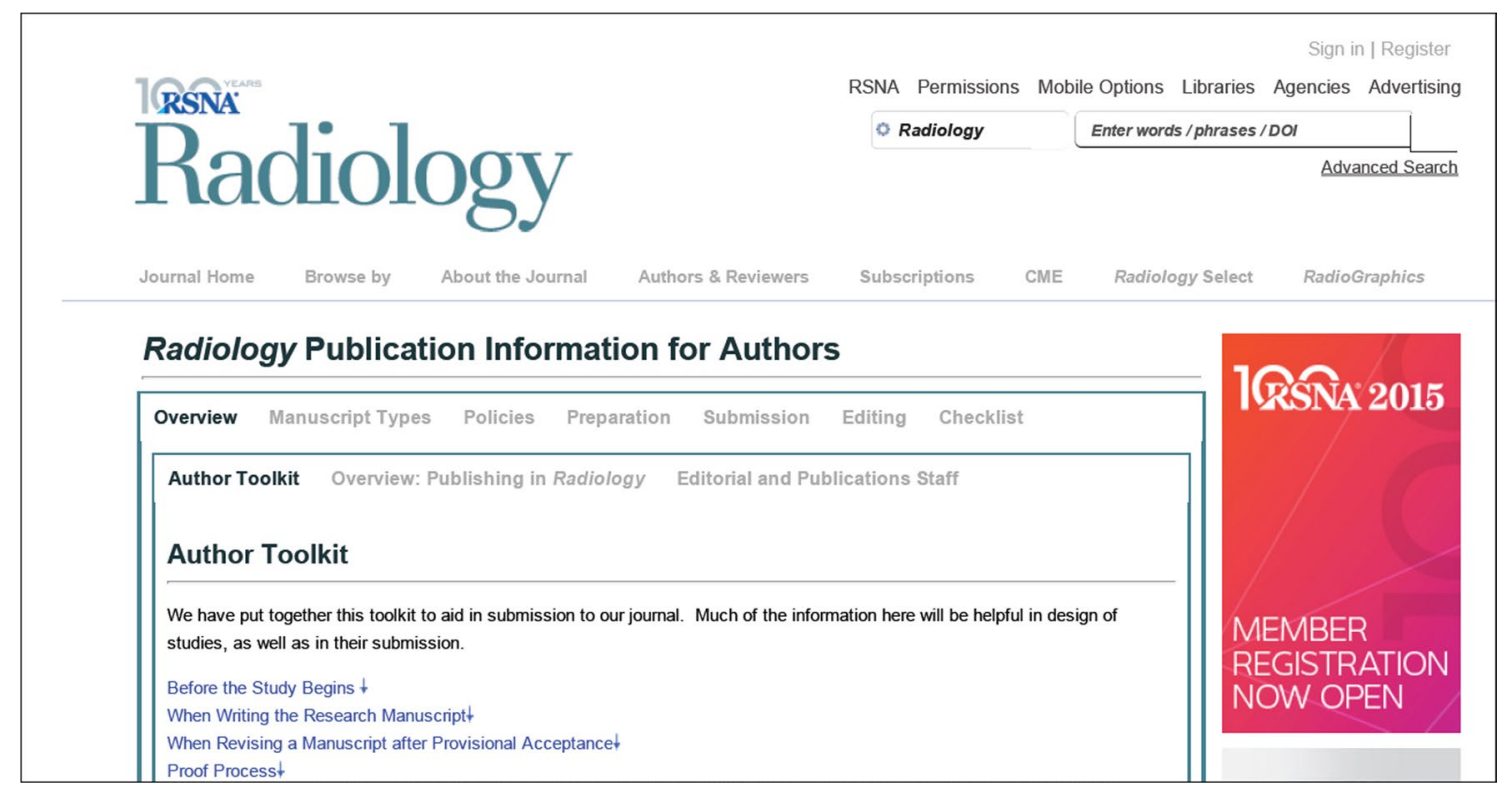

Fig. 1 Radiology publication information for authors. (http://pubs.rsna.org/page/radiology/pia)

with submission to our journal (Fig. 1). For studies dealing with diagnostic accuracy, at the time of manuscript preparation authors are requested to refer to the Standards for Reporting of Diagnostic Accuracy (STARD) checklist in the January 2003 issue of Radiology (Fig. 2) [4]. Likewise, for randomized controlled trials, authors should refer to the Consolidated Standards of Reporting Trials (CONSORT) statement; for meta-analysis of randomized controlled trials the Preferred Reporting Items for Systematic Reviews and Meta-Analyses (PRISMA) statement should be referred to. All correspondence should be sent to our manuscript central website (Fig. 3). Authors should select the appropriate category of submission before preparing the manuscript, because each category has specific formatting requirements (Table 1). Screening of the submitted materials is performed by the editorial office staff to check for adherence to author guidelines and completeness of submitted materials. Initial editorial pre-review of all submitted manuscripts is conducted by the Deputy Editor of an appropriate section (Table 2). Approximately $25 \%$ of submitted manuscripts are rejected at this stage after review by at least two Editors; the others are sent for external peer review. Factors that contribute to rejection of manuscripts by the Editors after editorial review include lack of novelty, scientific validity, and potential reader interest. Manuscripts accepted for full peer review are assigned to at least two experts in the relevant subspecialty of radiology. Each reviewer is given 2 weeks to review the manuscript. When the peer-review process is complete, reviewer comments and the manuscript are reviewed by the Deputy Editor, and a recommendation is made to the Editor in Chief. Those with a recommendation to potentially accept, or for which where the reviewers' recommendations are uncertain are discussed at our weekly Editorial Meeting, during which a final decision is made.

In our effort to encourage submission of high-quality manuscripts in competitive and rapidly developing areas, we recently introduced the option for Fast Track processing. As noted in the online author guidelines (accessible at http://pubs.rsna.org/page/radiology/pia\#fast),

Fast Track processing is designed to expedite the publication of articles in rapidly developing competitive areas such as molecular imaging, PET/CT and PET/ $\mathrm{MR}$, and cardiovascular imaging. Our goal is to publish these fast-track articles online, within 2 months of manuscript submission. To apply for fast-track processing, authors must submit a letter documenting the reasons that their manuscript is appropriate for Fast Track processing at the time the manuscript is submitted online through ScholarOne. A copy of this letter should also be sent directly to the Radiology Editorial office, radiology@rsna.org. These requests and the submitted manuscript will be reviewed by one of the editors, and the author will receive a determination as to suitability for fast-track processing within two working days of submission. Manuscripts not accepted for processing in fast-track will still be eligible for regular processing with the corresponding author's approval. Fast Track manuscripts will undergo expedited scientific and statistical peer review. We will limit the number of available editorial decisions to two; either acceptance or rejection. We will not offer the opportunity to resubmit 


\begin{tabular}{|c|c|c|c|}
\hline Section and Topic & Item \# & & On page \# \\
\hline $\begin{array}{l}\text { TITLEIABSTRACT/ } \\
\text { KEYWORDS }\end{array}$ & 1 & $\begin{array}{l}\text { Identify the article as a study of diagnostic accuracy (recommend MeSH heading } \\
\text { 'sensitivity and specificity'). }\end{array}$ & \\
\hline INTRODUCTION & 2 & $\begin{array}{l}\text { State the research questions or study aims, such as estimating diagnostic accuracy or } \\
\text { comparing accuracy between tests or across participant groups. }\end{array}$ & \\
\hline METHODS & & Describe & \\
\hline \multirow[t]{4}{*}{ Participants } & 3 & $\begin{array}{l}\text { The study population: The inclusion and exclusion criteria, setting and locations where } \\
\text { data were collected. }\end{array}$ & \\
\hline & 4 & $\begin{array}{l}\text { Participant recruitment: Was recruitment based on presenting symptoms, results from } \\
\text { previous tests, or the fact that the participants had received the index tests or the } \\
\text { reference standard? }\end{array}$ & \\
\hline & 5 & $\begin{array}{l}\text { Participant sampling: Was the study population a consecutive series of participants } \\
\text { defined by the selection criteria in item } 3 \text { and } 4 \text { ? If not, specify how participants were } \\
\text { further selected. }\end{array}$ & \\
\hline & 6 & $\begin{array}{l}\text { Data collection: Was data collection planned before the index test and reference } \\
\text { standard were performed (prospective study) or after (retrospective study)? }\end{array}$ & \\
\hline \multirow[t]{5}{*}{ Test methods } & 7 & The reference standard and its rationale. & \\
\hline & 8 & $\begin{array}{l}\text { Technical specifications of material and methods involved including how and when } \\
\text { measurements were taken, and/or cite references for index tests and reference standard. }\end{array}$ & \\
\hline & 9 & $\begin{array}{l}\text { Definition of and rationale for the units, cutoffs and/or categories of the results of the } \\
\text { index tests and the reference standard. }\end{array}$ & \\
\hline & 10 & $\begin{array}{l}\text { The number, training and expertise of the persons executing and reading the index tests } \\
\text { and the reference standard. }\end{array}$ & \\
\hline & 11 & $\begin{array}{l}\text { Whether or not the readers of the index tests and reference standard were blind } \\
\text { (masked) to the results of the other test and describe any other clinical information } \\
\text { available to the readers. }\end{array}$ & \\
\hline \multirow[t]{2}{*}{ Statistical methods } & 12 & $\begin{array}{l}\text { Methods for calculating or comparing measures of diagnostic accuracy, and the } \\
\text { statistical methods used to quantify uncertainty (e.g. } 95 \% \text { confidence intervals). }\end{array}$ & \\
\hline & 13 & Methods for calculating test reproducibility, if done. & \\
\hline RESULTS & & Report & \\
\hline \multirow[t]{3}{*}{ Participants } & 14 & When study was done, including beginning and ending dates of recruitment. & \\
\hline & 15 & $\begin{array}{l}\text { Clinical and demographic characteristics of the study population (e.g. age, sex, spectrum } \\
\text { of presenting symptoms, comorbidity, current treatments, recruitment centers). }\end{array}$ & \\
\hline & 16 & $\begin{array}{l}\text { The number of participants satisfying the criteria for inclusion that did or did not undergo } \\
\text { the index tests and/or the reference standard; describe why participants failed to receive } \\
\text { either test (a flow diagram is strongly recommended). }\end{array}$ & \\
\hline \multirow[t]{4}{*}{ Test results } & 17 & $\begin{array}{l}\text { Time interval from the index tests to the reference standard, and any treatment } \\
\text { administered between. }\end{array}$ & \\
\hline & 18 & $\begin{array}{l}\text { Distribution of severity of disease (define criteria) in those with the target condition; other } \\
\text { diagnoses in participants without the target condition. }\end{array}$ & \\
\hline & 19 & $\begin{array}{l}\text { A cross tabulation of the results of the index tests (including indeterminate and missing } \\
\text { results) by the results of the reference standard; for continuous results, the distribution of } \\
\text { the test results by the results of the reference standard. }\end{array}$ & \\
\hline & 20 & Any adverse events from performing the index tests or the reference standard. & \\
\hline \multirow[t]{4}{*}{ Estimates } & 21 & $\begin{array}{l}\text { Estimates of diagnostic accuracy and measures of statistical uncertainty (e.g. } 95 \% \\
\text { confidence intervals). }\end{array}$ & \\
\hline & 22 & $\begin{array}{l}\text { How indeterminate results, missing responses and outliers of the index tests were } \\
\text { handled. }\end{array}$ & \\
\hline & 23 & $\begin{array}{l}\text { Estimates of variability of diagnostic accuracy between subgroups of participants, } \\
\text { readers or centers, if done. }\end{array}$ & \\
\hline & 24 & Estimates of test reproducibility, if done. & \\
\hline DISCUSSION & 25 & Discuss the clinical applicability of the study findings. & \\
\hline
\end{tabular}

Fig. 2 STARD checklist for reporting diagnostic accuracy studies. Reproduced, with permission, from Bossuyt PM et al. Towards complete and accurate reporting of studies of diagnostic accuracy: the STARD initiative. Radiology 2003;226:24-8 


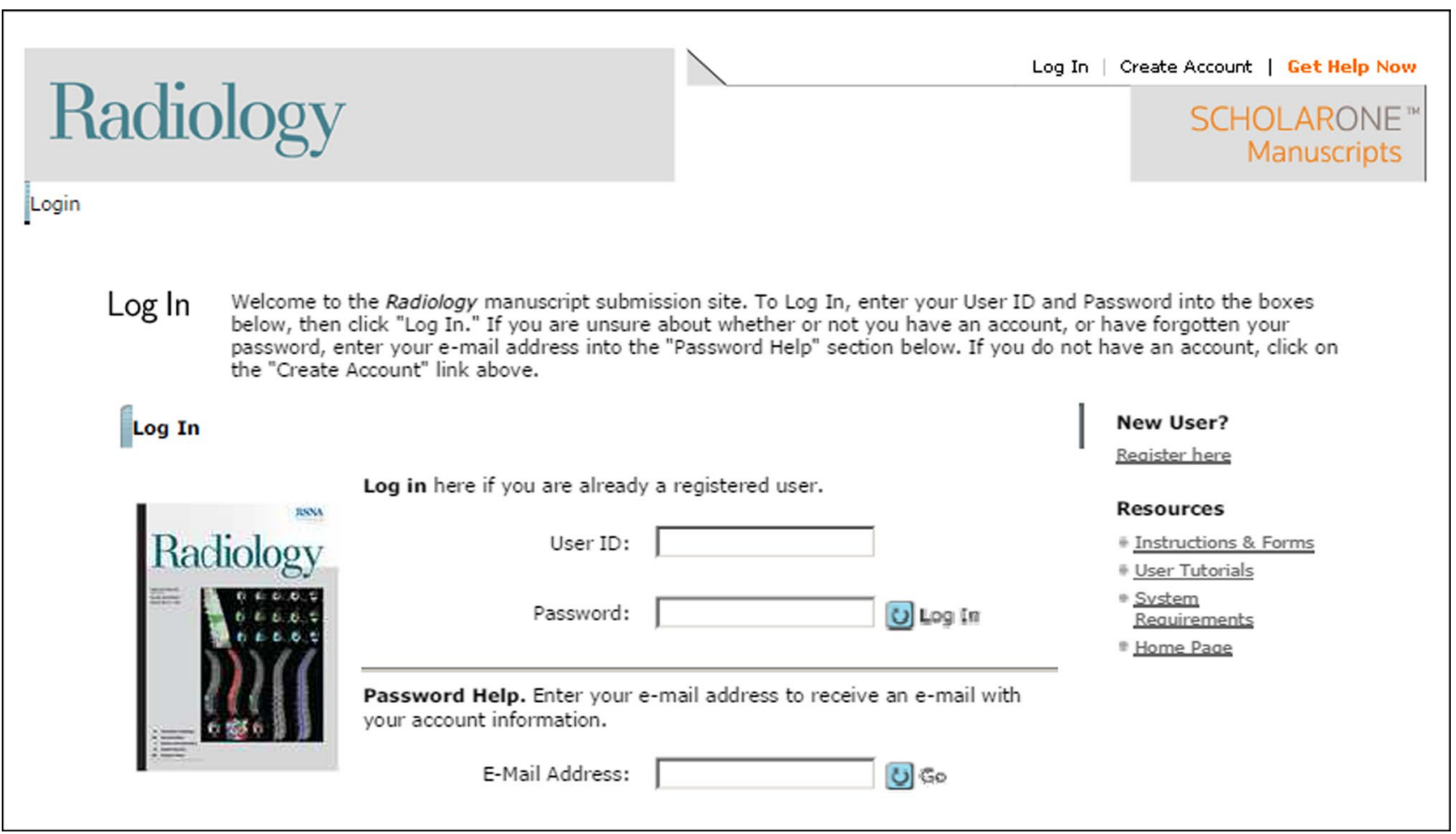

Fig. 3 Radiology online manuscript submission site. (https://mc.manuscriptcentral.com/rad)

or place manuscripts in the "under consideration" category if they have been processed on Fast Track. The authors of Fast Track manuscripts accepted for publication will be expected to submit their revised manuscripts within 2 weeks (ten business days) of our initial editorial decision. Once final acceptance is offered, the copy-editing and production of the manuscripts as well as their posting online will be prioritized and expedited.

\section{Editorial decisions}

We use four editorial decision categories.

Papers that are accepted for publication at the Editorial meeting will undergo further review by a statistician to ensure the validity and accuracy of the methods of analysis and the conclusions reached. After this statistical review, the manuscripts undergo "scientific editing" and then a decision letter is sent to the authors. Revised manuscripts, when resubmitted, may undergo further external review, if needed, before final acceptance for publication.

When the decision is "Under Consideration", the paper is neither accepted nor rejected, although ultimately between 80 and $90 \%$ of manuscripts with this decision will be accepted for publication. Authors are asked to revise their manuscript to address important issues that have been identified by the peer review process before a decision to accept or reject is given. In general this will require including additional data or further analysis. It is very important that authors respond effectively to specific issues identified by the Editors and/or the reviewers and revise the manuscript accordingly before resubmitting the manuscript for reconsideration. If not satisfactorily revised, the paper will be rejected.

The decision "reject, allow resubmission" allows resubmission of a revised manuscript after issues raised by the reviewers have been addressed, as deemed appropriate, to improve the manuscript. We do not specifically require any of the reviewers comments to be addressed Resubmitted manuscripts are treated as new submissions and undergo a new peer-review process; they are usually sent to three reviewers, once of whom reviewed the original submission. Authors are advised to use the reviewers' comments as they deem most appropriate to improve their submission. They are not required to send a point by point response to the reviewers' comments. Approximately $30 \%$ of those manuscripts with this editorial decision will be accepted for publication if resubmitted.

If the decision is to "reject", resubmission of the same manuscript is not allowed. This decision is taken when the submitted manuscript is not sufficiently novel or original to advance scientific knowledge of the subject matter.

Original research papers may describe new a diagnostic method, imaging modality or technique, or a new 


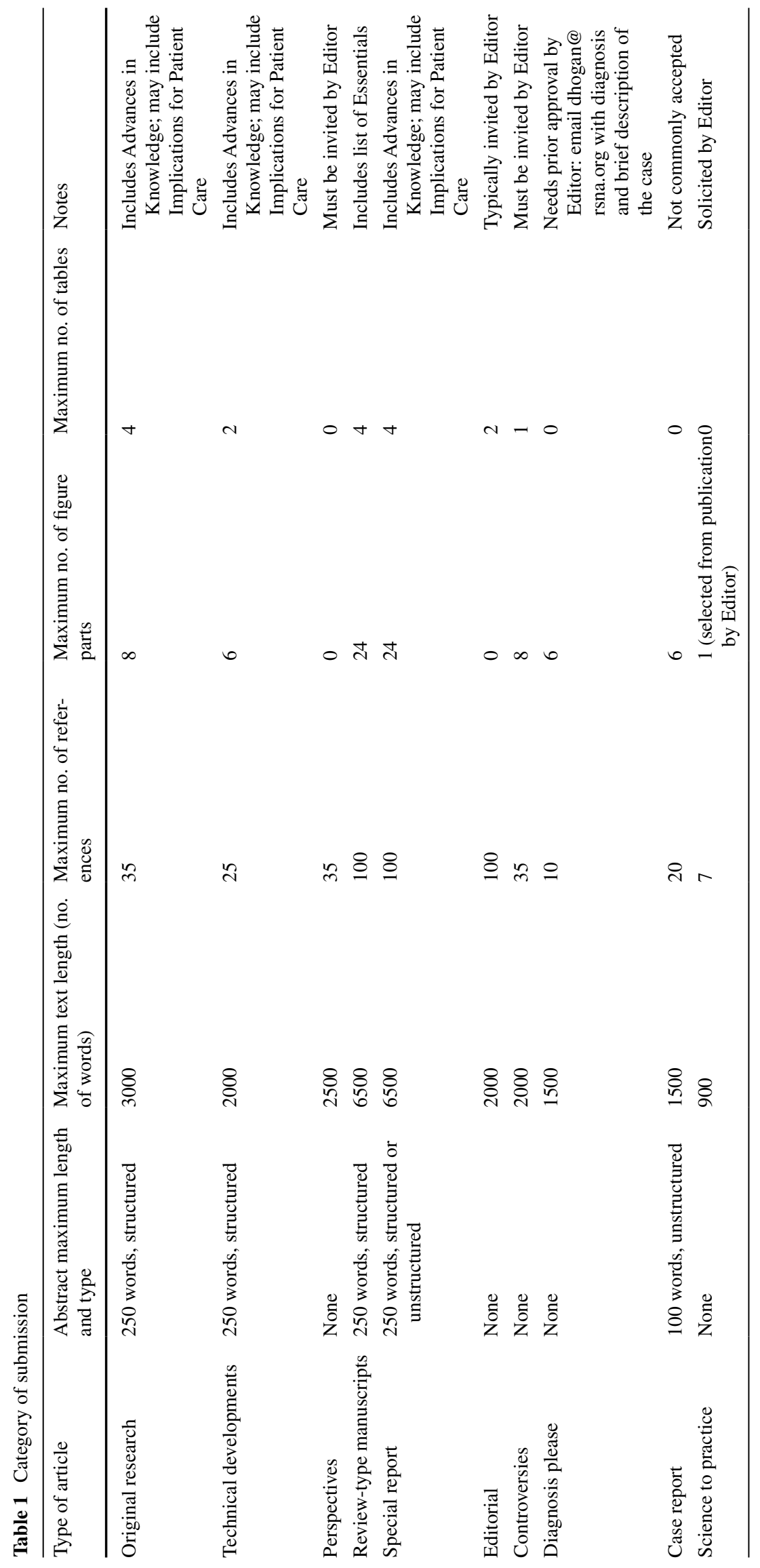


application of an existing modality or technique; they may provide new insights into anatomy and disease processes, describe new image-processing methods, or report imaging findings of a new disease. Examples of papers describing these are summarized in Table 3 [5-11]. Although we consider novelty and originality to be particularly important, please avoid claims of priority when writing a manuscript. Each paper may be accepted for publication on the basis of its novelty and potential importance; it is unnecessary in this setting to explicitly state "we were first".

\section{Where to obtain ideas}

To obtain novel and original ideas for original research studies, we suggest authors start by conducting a PubMed

Table 2 Editorial board of the journal Radiology

\begin{tabular}{ll}
\hline Sections & Editor \\
\hline $\begin{array}{l}\text { Editor-in-chief } \\
\text { Gastrointestinal Imaging, Genitourinary Imag- } \\
\text { ing, Nuclear Medicine, Pediatrics, Health }\end{array}$ & Herbert Y. Kressel \\
Policy and Practice, Technical Developments, & \\
$\quad$ Experimental Studies, Molecular Imaging, & \\
$\quad$ Medical Physics sections & \\
Senior Deputy Editor & Deborah Levine \\
Ultrasound and Breast section & \\
Chest section & Alexander Bankier \\
Cardiac section & Albert de Roos \\
Musculoskeletal section & Ali Guermazi \\
Neuroradiology section & David F. Kallmes \\
Interventional Radiology section & David C. Madoff \\
\hline
\end{tabular}

search to discover what is already known and what is still unknown about their topic of interest. Identify the question that needs to be answered by a new study. Table 4 lists important things authors should consider when conducting an original research study. For radiological studies, authors should, in particular, screen recent published articles in major radiological journals.

Radiologists are also encouraged to attend Radiological Society of North America meetings held annually in Chicago, USA. By observing how other people conducted and presented their studies, one may gain inspiration about how to conduct a study. Seeing the award-winning presentations is particularly helpful and educational. As authors plan a new study, they should formulate a meaningful hypothesis. Hypothesis-driven original research has a higher chance of acceptance for publication. Authors should also plan analytical methodology to ensure validity and adequate statistical power to demonstrate results are statistically significant. It is important to consult expert statisticians ensure the analytical methodology is appropriate. We also recommend authors consult other relevant experts and potential collaborators including, but not limited to, pathologists and $\mathrm{PhD}$ scientists (e.g. physicists, radiological scientists, biomedical engineers).

\section{Studies that have higher likelihood of acceptance}

High-quality written English is very important so that the ideas in the manuscript can readily understood. Always proofread the manuscript, and consult a professional English editor when necessary. Please note that both grammar

Table 3 Examples of papers published in Radiology and what they described

\begin{tabular}{|c|c|c|}
\hline Key aspect of the paper & Ref. & Example of published paper \\
\hline New diagnostic method/imaging modality/technique & {$[5]$} & $\begin{array}{l}\text { Yamada I, et al. Gastric carcinoma: ex vivo MR imaging at } 7.0 \mathrm{~T} \text { - correlation with } \\
\text { histopathologic findings. Radiology } 2015 ; 275: 841-8\end{array}$ \\
\hline New application of existing modality/technique & {$[6]$} & $\begin{array}{l}\text { Hayashi D, et al. Detection of osteophytes and subchondral cysts in the knee with } \\
\text { use of tomosynthesis. Radiology 2012;263:206-215 }\end{array}$ \\
\hline New image processing methods & [7] & $\begin{array}{l}\text { Ohno Y, et al. Three-way comparison of whole-body MR, co-registered whole-body } \\
\text { FDG PET/MR, and integrated whole-body FDG PET/CT imaging: TNM and } \\
\text { stage assessment capability for non-small cell lung cancer patients. Radiology } \\
\text { 2015;275:849-61 }\end{array}$ \\
\hline New insight into anatomy (cadaveric study) & {$[8]$} & $\begin{array}{l}\text { Wagner FV, et al. Capsular ligaments of the hip: anatomic, histologic, and positional } \\
\text { study in cadaveric specimens with MR arthrography. Radiology 2012;263:189-198 }\end{array}$ \\
\hline New insight into disease process & [9] & $\begin{array}{l}\text { Guermazi A, et al. Medial posterior meniscal root tears are associated with develop- } \\
\text { ment or worsening of medial tibiofemoral cartilage damage: the Multicenter } \\
\text { Osteoarthritis Study. Radiology 2013; 268:814-821 }\end{array}$ \\
\hline Imaging findings of a new disease & {$[10]$} & $\begin{array}{l}\text { Wang O, et al. Emerging H7N9 influenza A (novel reassortant avian-origin) pneu- } \\
\text { monia: Radiologic findings. Radiology } 2013 ; 268: 882-889\end{array}$ \\
\hline Experimental and clinical trial & {$[11]$} & $\begin{array}{l}\text { Fukawa T, et al. Quantitative assessment of tendon healing by using MR T2 map- } \\
\text { ping in a rabbit Achilles tendon transaction model treated with platelet-rich } \\
\text { plasma. Radiology } 2015 \text { Mar 27:141544. [Epub ahead of print] }\end{array}$ \\
\hline
\end{tabular}


Table 4 Things to consider when conducting an original research study

Change practice: "News you can use"

Help us understand biology or technology

Generate a new hypothesis and stimulate further research

Add substantially to available information

Have conclusions that provide clear direction

Provide useful information

and flow of sentences and paragraphs (i.e. "readability") are important. Authors should choose a topic that is likely to attract much reader interest. Such topics include those appealing to general clinical radiologists world-wide; which significantly advance knowledge; are likely to have significant effect on daily clinical practice; and include findings that are generalizable (i.e. not just applicable to the institution at which the study was conducted).

Authors should try to write a convincing Introduction-write a succinct summary of a literature review (as a guide, a maximum of 1.5 pages, double-spaced), clearly explain why the study was conducted, and clearly define the objective(s) of the study. For further complete details of how to formulate the Methods and Results sections, refer to the aforementioned online Publication Information for Authors, and the STARD, CONSORT, and PRISMA statements cited above.

The Discussion section should be well-structured. Begin with a concise summary of the study. This should be followed by a relevant literature review, although simple repetition of what has already been written in the Introduction section should be avoided. Here, authors should provide more in-depth analysis of the relevant literature evidence in the context of the study conducted, emphasizing how the study differed from previously published studies. Describe study limitations in a paragraph immediately before the last paragraph of the Discussion. Finally, state the conclusion of the study, which should be directly based on the evidence presented in the Results section.

Authors are discouraged from conjecture, over-interpretation of results, and making overly enthusiastic statements. This is a common error. Unpublished non-peer-reviewed work conducted by the authors or other researchers should not be cited in any form, because unpublished work has not undergone peer review and we do not know whether such data are valid, reliable, or even meaningful. Also, authors should not state what they plan to do in the future, or anything not reported in the current manuscript will be reported in a future paper, unless the authors have performed feasibility or hypothesis-generating studies.

When preparing figures for publication, ensure these are of high quality and high resolution $(300 \times 300$ dpi). Refer to the Radiology author guidelines for complete details
[3]. Illustrations and figures should convey key messages visually; therefore be sure to use the correct annotations (arrows, arrowheads, etc.). Color figures should be used only when essential-for simple graphs gray scale is often sufficient. If you include too many figures, reviewers will probably ask to reduce the number, although when necessary we can publish additional figures as an online-only appendix. Tables should be summaries of important analysis results. Make these as concise and simple as possible. If a table is too large or overly complicated, readers will not read the whole table and will not be able to determine what the most important data are. Ensure $p$-values are to the third decimal place (e.g. 0.002), unless they are less than 0.001 (in which case state $p<0.001$ ).

\section{Conclusion}

In summary, we encourage submission of high-quality papers from Japanese colleagues and hope this article includes information pertinent to preparation of a manuscript reporting an original research study which has a high likelihood of being accepted for publication. Prospective authors should read our guidelines thoroughly. Crucial issues that increase the chance of a manuscript being accepted include high-quality English, clear explanation of the rationale behind the study, clear explanation of valid methodology, concise presentation of results with effective use of figures and tables, and meaningful discussion which includes the limitations of the study. We hope this article will help prospective authors in Japan and stimulate motivation to conduct and publish high-quality original research studies. We note that the Japanese Journal of Radiology is an emerging journal that publishes original research articles and review papers [12], with an impact factor increasing year by year, and we sincerely hope this positive trend continues [13]. We also hope that this article will serve as a bridge between the two journals Radiology and Japanese Journal of Radiology.

\section{Compliance with ethical standards}

Conflict of interest Ali Guermazi serves as a consultant to MerckSerono, Ortho-Trophix, Genzyme, and TissueGene, and is the President and a shareholder of Boston Imaging Core Lab, LLC. Herbert Kressel has no conflict of interest.

\section{References}

1. Kanda T, Ishii K, Kawaguchi H, Kitajima K, Takenaka D. High signal intensity in the dentate nucleus and globus pallidus on unenhanced T1-weighted MR images: relationship with increasing cumulative dose of a gadolinium-based contrast material. Radiology. 2014;270:834-41. 
2. Satoh Y, Onishi H, Nambu A, Araki T. Volume-based parameters measured by using FDG PET/CT in patients with stage I NSCLC treated with stereotactic body radiation therapy: prognostic value. Radiology. 2014;270:275-81.

3. Radiology publication information for authors. http://pubs.rsna. org/page/radiology/pia.

4. Bossuyt PM, Reitsma JB, Bruns DE, Gatsonis CA, Glasziou PP, Irwig LM, et al. Towards complete and accurate reporting of studies of diagnostic accuracy: the STARD initiative. Radiology. 2003;226:24-8.

5. Yamada I, Miyasaka N, Hikishima K, Kato K, Kojima K, Kawano T, et al. Gastric carcinoma: ex vivo MR imaging at 7.0T-correlation with histopathologic findings. Radiology. 2015;275:841-8.

6. Hayashi D, Xu L, Roemer FW, Hunter DJ, Li L, Katur AM, et al. Detection of osteophytes and subchondral cysts in the knee with use of tomosynthesis. Radiology. 2012;263:206-15.

7. Ohno Y, Koyama H, Yoshikawa T, Takenaka D, Seki S, Yui M, et al. Three-way comparison of whole-body MR, co-registered whole-body FDG PET/MR, and integrated whole-body FDG PET/CT imaging: TNM and stage assessment capability for nonsmall cell lung cancer patients. Radiology. 2015;275:849-61.
8. Wagner FV, Negrao JR, Camos J, Ward SR, Haghigh P, Trudell DJ, et al. Capsular ligaments of the hip: anatomic, histologic, and positional study in cadaveric specimens with MR arthrography. Radiology. 2012;263:189-98.

9. Guermazi A, Hayashi D, Jarraya M, Roemer FW, Zhang Y, Niu J, et al. Medial posterior meniscal root tears are associated with development or worsening of medial tibiofemoral cartilage damage: the Multicenter Osteoarthritis Study. Radiology. 2013;268:814-21.

10. Wang O, Zhang Z, Shi Y, Jiang Y. Emerging H7N9 influenza A (novel reassortant avian-origin) pneumonia: radiologic findings. Radiology. 2013;268:882-9.

11. Fukawa T, Yamaguchi S, Watanabe A, Sasho T, Akagi R, Muramatsu Y, et al. Quantitative assessment of tendon healing by using MR T2 mapping in a rabbit Achilles tendon transaction model treated with platelet-rich plasma. Radiology. 2015;27:141544 (Epub ahead of print).

12. Nakayama T, Ehara S. Spondylolytic spondylolisthesis: various imaging features and natural courses. Jpn J Radiol. 2014;33:371.

13. Tamaki N. The year for our new endeavor: 2015. Jpn J Radiol. 2014;33:365. 